Stoa,

Vol. 1, No. 1, 2010, pp. 47-75.

ISSN en trámite.

\title{
LA PROPUESTA METAFÍSICA DE ZUBIRI, ESBOZADA \\ DESDE EL PROBLEMA DE LA INTELECCIÓN
}

\author{
José Antonio Hernanz Moral \\ Instituto de Filosofía \\ Universidad Veracruzana \\ jhernanz@uv.mx
}

RESUMEN: La metafísica de Zubiri se centra en el valor teórico de la idea de "sustantividad", frente a la de "sustancia" que desde Aristóteles ha sido para muchos autores el cimiento sobre el que se construye la filosofía primera. Este novedoso planteamiento surge de una reconfiguración de la idea misma de metafísica, que se exige por una parte una orientación fenomenológica (en el caso de Zubiri bastante heterodoxa) y por otra la coherencia con la ciencia. Este artículo ratrea y revisa la relación entre la categoría "sustantividad" y los tres momentos en los que se da la intelección sentiente, "aprehensión primordial de la realidad", "logos" y "razón".

PALABRAS CLAVE: intelección sentiente y sustantividad; crítica a la metafísica; ciencia y metafísica; filosofía de Zubiri; epistemología contemporánea.

SUMMARY: Zubiri's metaphysics focuses on the theoretical value of "sustantivity" versus "substance", the one that since Aristotle has been for many writers the foundation on which first philosophy is builded. This new approach comes from a reconfiguration of the idea of metaphysics, which requires on one hand a phenomenological orientation (rather heterodox in Zubiri) and on the other cohererence with science. This paper searchs and reviews the relationship between the category "sustantivity" and the three modes of sentient intellection, "primordial apprehension of reality", "logos" and "reason".

KEY WORDS: sentient inteligence and sustantivity, critics on metaphysics, science and metaphysics, Zubiri's philosophy, contemporary epistemology.

El sustrato de la metafísica

Zubiri se cuestiona por la índole de la metafísica; para él está medianamente claro que metafísica y filosofía son materialmente la misma cosa: no es "parte" de la filosofía, sino que es materialmente idéntica a la filosofía (Zubiri 1994, 
p. 16). "Filosofía" designa, a partir de Sócrates, la actitud de los hombres que buscan la sabiduría suprema, la sabiduría radical de la vida y de las cosas. En ese aspecto, "metafísica" es algo más, consiste en dar carácter preciso a aquello en que consiste la ultimidad radical que busca la filosofía; he ahí para Zubiri la diferencia, formal -y no material-, entre filosofía y metafísica: "la metafísica es la definición 'real' de lo que es la filosofía tomada en términos generales. Metafísica es la definición formal de la filosofía” (ibídem, p. 17).

Esto será así siempre que circunscribamos nocionalmente de un modo correcto, indica Zubiri, en qué consiste la ultimidad a que apunta la filosofía. Eso se podrá saber analizando los dos componentes de la palabra: "meta" y "física". Con metá se quiere decir que la metafísica apunta hacia algo que se encuentra "allende" (ibídem): "metá" será, por tanto, trascender, estar allende. Allende apunta, inicialmente, a lo obvio: cuando el hombre se dirige a las cosas, éstas le salen al paso, de suerte que las cosas, vistas de este modo, constituyen el dominio de lo "obvio". Así "las cosas que le salen a uno al camino son las cosas obvias. Por consiguiente, explicar la palabra 'allende' consiste en explicar lo 'obvio', allende lo cual (...) se lanza la filosofía” (ibídem). Ir allende lo obvio podría entonces consistir en ir allende las cosas que se encuentran y nos salen al paso en el contacto inmediato con la realidad. Tal sería el caso, dice Zubiri, de la ciencia, en la que allende sería lo "ultra-obvio". ${ }^{1}$ Sin embargo, ese no es el sentido que define el "metá" de la metafísica. Más bien se centrará en lo "diáfano", esto es, en aquello que no percibimos por estar constitutivamente inscrito en lo obvio; en este sentido para Zubiri lo diáfano es "trascendental". Lo es "no en el sentido de que sea una cosa muy importante, pero sí en el sentido de que transciende en una u otra forma a las cosas que son obvias, sin estar, sin embargo, fuera de las cosas obvias" (ibídem, p. 19). Precisamente en la diafanidad estriba la dificultad de la metafísica: es la ciencia de lo diáfano, y consiste en el ejercicio de la visión violenta de lo diáfano.

Zubiri entiende, por tanto, la marcha de la filosofía como un ir a lo diáfano. En ello estriba la marcha a lo trascendental, por lo que, del mismo modo que metafísica es la definición de filosofía, trascendentalidad es la definición de metafísica, con lo que nos encontramos con esos tres momentos, filosofía,

${ }^{1}$ Cfr. ibídem. 
metafísica, trascendentalidad, concatenados en nuestra búsqueda de lo radical de lo real.

En su desarrollo, Zubiri manifiesta que la visión de lo diáfano, curiosamente, es violenta, ya que no se trata de algo obvio, sino de lo que se encuentra en todas las cosas, y ya que la violencia estriba en tratar de ver la claridad, mas sin salir de esa claridad misma: ${ }^{2}$ la preocupación de la filosofía no es sacarnos de las cosas, sino retenernos en ellas para ver lo diáfano. La diafanidad es problemática; tanto es así que Zubiri nos advierte que es "algo que está precisamente en todas las cosas y que, si no percibimos o no nos ponemos a pensar en este momento de que las cosas son, es porque es tan diáfano que lo único que pensamos es en aquello que las cosas son". ${ }^{3}$

Todo eso cabe decir sobre el "metá"; pero también hay que hacer una salvedad, cree Zubiri, sobre lo "físico": es un término que no designa sino a las cosas tal como son; la ultimidad de la diafanidad del "metá" consiste es estar allende las cosas tales como son, esto es, lo "físico". La metafísica se constituye como ir a lo diáfano allende las cosas tal como son. La última diafanidad que aquí se busca es lo fundamental: la fundamentalidad de la metafísica. ${ }^{4}$

Lo fundamental en la metafísica no se encuentra en que sea ciencia con fundamentos, esto es, que tenga razones y principios, sino que lo radical en este caso es que la metafísica "está determinada justamente por aquello que es lo metafísico de las cosas, lo diáfano que nos importa y nos arrastra consigo. Lo metafísico es diafanidad última de las cosas, de lo real. Y sólo arrastrados por esta claridad puede constituirse la metafísica como ciencia" (ibídem, p. 29).

En definitiva, el problema de la metafísica es la expresión intelectual de esa violencia que caracteriza la visión de lo diáfano, es la estructura de la diafanidad, de la transcendentalidad en sí misma.

Para Zubiri esto es así porque la filosofía y la metafísica occidentales son una filosofía de la transcendentalidad. ${ }^{5} \mathrm{El}$ orden transcendental es en sí problemático, consta de una textura intrínsecamente problemática, a partir de la

${ }^{2}$ Cfr. ibídem, pp. 21-22.

${ }^{3}$ Aunque hay que aceptar esto con cierto cuidado: "No es, bien entendido, más que un ejemplo y (...) un ejemplo traidor", ibídem, p. 25.

${ }^{4}$ Cfr. ibídem, p. 16

${ }^{5}$ Cfr. ibídem, pp. 32-33 
cual se plantean los problemas que el propio orden transcendental encierra. Paralelamente, este autor considera que el problematismo y la conceptuación del orden transcendental se han venido apoyando en la unidad primaria y radical entre ratio, intellectus ynous ${ }^{6}$ unidad que revisa en virtud de los desarrollos de la noción de inteligencia sentiente.

En efecto, en el marco de la intelección sentiente la razón no es sino la inteligencia situada en "hacia", de suerte que la inteligencia se propone buscar las cosas por estar llevada por la realidad en el modo de "hacia". Así mismo "en esta ida 'hacia' el objeto, en esta 'quaerencia', en este intellectus quarens que va hacia el objeto, la razón hace muchas cosas (...). Pero no es esto lo único que hace porque, al final de todo eso, la inteligencia necesita confrontar todo lo que ha buscado con la realidad que está inmediata y primariamente presente. En ese momento, las cosas dan o quitan la razón al hombre" (ibídem, pp. 343-344).

Entendida así la fundamentalidad de la metafísica, no puede sino resultar problemática. La problematicidad de la metafísica, empero, no apunta a que en ella haya una serie de problemas - de mayor o menor importancia-, sino a lo problemático no sólo de esta ciencia, sino de lo metafísico de las cosas. Lo metafísico de las cosas no es algo que se encuentre ahí, sino que es algo que hay que hacer. Ahí se encuentra, para Zubiri, lo genuinamente radical de la problematicidad de la metafísica.

Ahora bien, propuesta metafísica zubiriana se da en un sustrato intelectual de doble raíz: un legado fenomenológico y el interés por mantener estrictamente una coherencia con los conocimientos científicos contemporáneos. Estos ejes articulan la reflexión filosófica de este autor, de suerte que ambos son de igual importancia, al menos en mi opinión. Ninguno sobresale sobre el otro, y los dos son necesarios. Ambos incidirán, como se verá en la segunda parte de este artículo, en la inserción del problema de la realidad en el de la intelección y viceversa.

\subsection{La raíz fenomenológica}

El impacto de la fenomenología en Zubiri es claro y determinante en su trayectoria filosófica; no en vano él mismo cataloga la primera etapa de su pen-

${ }^{6}$ Cfr. ibídem, p. 324. 
samiento de "fenomenológica", aunque para, llegado el momento, desvincularse por completo de la etiqueta de "fenomenólogo". Sin embargo, no resulta demasiado difícil seguir el vívido rescoldo fenomenológico a lo largo de la filosofía madura de Zubiri. Tanto caló en su pensamiento la presencia de un horizonte fenomenológico que quizá no hace otra cosa que desplegarlo en su más íntima radicalidad. No puede negarse, en mi opinión, la orientación fenomenológica de la trilogía de la intelección, que directamente repercute en la noción misma de sustantividad, a la que estamos dedicando nuestro esfuerzo en esta investigación. Vayamos, por tanto, a las fuentes de las que el joven Zubiri bebe, para así comprender con mayor nitidez el significado de su aportación metafísica. Esas fuentes nos conducen inequívocamente a Husserl, y más en concreto a lo que Husserl estima como el problema central de la filosofía: el fenómeno. El fenómeno es aquello sobre lo que debemos reflexionar, en la consecuente reducción fenomenológica. "Fenómeno", para Zubiri, no es término de determinación de estado mental en Husserl, principalmente porque los estados mentales son estados reales de los que no podemos determinar si tienen más realidad que el objeto de una percepción externa; tampoco entiende por "fenómeno" lo aparente de una cosa allende su aparecer, porque en esa contraposición no se nos indica qué es lo aparente mismo. "Fenómeno" es, sin más, lo que es manifiesto en tanto que es manifiesto, al tiempo que

todo fenómeno, todo cogitatum, lo es tan sólo según los modos del cogitante y de su cogitación. Esta cogitación es lo que Husserl llama la conciencia. (...) Fenómeno y conciencia son [para Husserl] dos términos correlativos: toda conciencia es conciencia de algo, y este algo es el fenómeno que se da en aquella conciencia. Así como fenómeno no es apariencia subjetiva, así tampoco conciencia es un estado subjetivo. La correlación en cuestión está por encima de todo dualismo sujetoobjeto en el sentido de realidades. ${ }^{7}$

Todo queda, pues, reducido a puro fenómeno, lo que para Husserl se trata de una "reducción fenomenológica". Esta reducción es de un modo tal que opera sobre la totalidad del mundo, es decir, sobre la totalidad de las cosas reales (incluido el hombre mismo); vivir en el mundo será, por tanto, una actitud "natural". Aquí se encuentra un punto básico para comprender la pos-

${ }^{7}$ Zubiri 1963, p. 216. 
tura de Husserl: en la vida natural hay un fundamento, la "proto-creencia" en la realidad de todo, y en ese fundamento se cimienta toda ulterior creencia. ${ }^{8}$

Ahora bien, la reducción adquiere un dinamismo propio, que pasa por dejar en suspenso, mientras vivo en el mundo real, la validez de la creencia en su realidad. Esto no significa negar la creencia en él, sino abstenernos de ella, hacer una epoché ante ella. Ese dinamismo adquirirá, en consecuencia, una doble dimensión:

En primer lugar, en el acto mismo de suspensión, todo lo que se presentaba como un hecho deja de ser fáctico. El hecho es siempre y sólo la realización de algo en su concreción individual. Si suspendo este carácter de hecho, lo que se me aparece es simplemente la configuración intrínseca que posee lo dado. En lugar del puro hecho tenemos el eidos. Si en este rojo de hecho, prescindo de que sea 'de hecho' rojo, me quedo con 'lo rojo'.(...) Pero no solamente esto. Lo más importante es que se reduce la realidad en su mismo carácter de realidad. Con lo cual el mundo reducido a fenómeno resulta ser perfectamente irreal, (...) prescinde, por epoché, de toda alusión a la realidad (ibídem, p. 218).

$\mathrm{Al}$ ser el mundo irreal, la reducción no es sólo eidética, sino también, fundamentalmente, trascendental. La reducción es trascendental ya que el fenómeno en su irrealidad se da en la conciencia y en el acto de conciencia que es la reducción, al mismo tiempo que refleja adecuadamente la idea de "trascendental”: aquello en lo que todo coincide por ser. ${ }^{9}$ Fenomenalidad es el carácter trascendental por excelencia.

Continúa Zubiri afirmando que, partiendo de esta reducción a fenómeno, Husserl estima la esencia como genuino ámbito de la investigación filosófica, de suerte que el fenómeno puro, tanto en la dimensión eidética como en la trascendental, es esencia; la esencia es objeto de la filosofía, y objeto absoluto; ${ }^{10}$ paralelamente, su manifestación en la conciencia es absoluta también: al suspender el carácter de realidad, nos quedamos con lo percibido tal como se manifiesta y en tanto que se manifiesta en la conciencia.

El saber de la esencia será por tanto el metro del saber de la realidad; el saber absoluto de la esencia, esto es, el saber fenomenológico, justifica cualquier saber de hecho: el saber filosófico es, en definitiva, fenomenología.

${ }^{8}$ Cfr. ibídem, p. 217

${ }^{9}$ Cfr. ibídem, p. 219.

${ }^{10}$ Cfr. ibídem, p. 222. 
Filosofía es, así, ciencia rigurosa y estricta de la esencia; no es sistema racional de proposiciones y demostraciones, sino evidenciación intuitiva; ${ }^{11}$ será una ciencia sistemática, pero del sistema de lo manifiesto en cuanto manifiesto. Entendida de esta manera, la filosofía no supone una mera estratificación de problemas, sino que ha de dirigirse a un problema filosófico radical, que para Husserl no es otro que la constitución.

La constitución, tal como Husserl la entiende, trae consigo una nueva idea de la subjetividad, ajena al subjetivismo psicológico, al sujeto trascendental kantiano y al objetivismo: la subjetividad es algo constituyente, esto es, consiste en un hacer que las cosas vayan manifestándose, dándose a la conciencia tal como son en sí; de este modo, y desde el sistema de mis vivencias, el mundo se va constituyendo y queda constituido como sentido de mi ego en él. ${ }^{12}$

Mas fijémonos por un momento en la evolución sufrida por la corriente fenomenológica, antes de centrarnos en lo que Zubiri acepta o rechaza de ella. La idea motriz en el pensamiento de Husserl es la búsqueda de una filosofía sin presupuestos, que así permitirá la convergencia entre todos. Pronto ese intento quedaría truncado, ya que, recordemos, antes de 1930 se podía hablar distintamente de la fenomenología de Husserl, de la de Heidegger y de la Scheler, y esa diversificación nos lleva a preguntarnos si bajo la denominación genérica de "fenomenología" hay diversas filosofías distintas, o distintos intentos de realizar el cometido filosófico que la fenomenología se propone. Zubiri se decanta más bien por la segunda de esas opciones, ${ }^{13}$ de modo que estima que la fenomenología, más que una filosofía, es algo previo a ella, una idea de filosofía, que puede plasmarse diversamente en sistemas filosóficos distintos, pero que comparten una misma fuente directriz:

(...) lo importante es que todas esas concepciones suponen que la fenomenología se ha propuesto de antemano claramente, como tema de la filosofía, una tarea unívoca cuya realización constituiría toda la razón de su existencia. (...) La fenomenología no ha partido de una idea acabada de lo que se propone, porque ello supondría una idea acabada de lo que la fenomenología entiende por filosofía; y la filosofía no ha partido de una idea acabada de lo que entiende por filosofía. Más bien ha acontecido lo contrario. Ha ido adquiriendo paulatinamente esa idea en el curso del filosofar efectivo. Y semejante curso no es una evolución o transfor-

${ }^{11}$ Cfr. ibídem, p. 234.

${ }^{12}$ Cfr. ibídem, p. 244.

${ }^{13}$ Cfr. Pintor 1979, p. 86. 
mación de unos conceptos en otros, sino más bien el madurar un mismo intento integral latente que sólo en su madurez puede ser descubierto. ${ }^{14}$

Zubiri ve en la fenomenología un esfuerzo crítico que permite filosofar verdaderamente, sin ceñirnos de antemano a un determinado círculo filosófico, ve en ella la creación de un ámbito donde poder filosofar libremente. ${ }^{15}$ Ahora bien, a pesar de lo novedoso que resulta, no por ello rompe drásticamente con la tradición filosófica; la fenomenología tiene por objeto la realización consecuente, a la altura de su tiempo, de los objetivos de la modernidad: un ideal de saber acorde con la razón y ajena a presupuestos que lo coarten. No olvidemos que Husserl ve su filosofía como un "neocartesianismo", que pretende superar los fracasos de Descartes, debidos por otra parte -en su opinión-a la falta de fidelidad de este autor con sus presupuestos.

Hay un punto, sin embargo, en el que no tardará en aparecer la discrepancia: la conciencia como punto de partida. ${ }^{16}$ En opinión de Husserl, un saber sin presupuestos y evidente precisa de la conciencia como punto inicial, ya que en ella se da la necesaria inmediatez que lleva a la transparencia del saber. De este modo, las cosas son cosas en tanto que ofrecen un "sentido" a la conciencia intencional; el problema se manifiesta inmediatamente: esa exigencia de la conciencia bien puede ser un presupuesto racionalmente incontrolable. Zubiri centra en esa deficiencia toda la crítica a la fenomenología de Husserl; ${ }^{17}$ la radicalidad de la conciencia debe ser superada, pues limita, a ojos del autor español, cualquier esfuerzo fructífero en la especulación filosófica.

Para concretar esa crítica Zubiri sigue la estela de otro gran autor, Heidegger, que, como vimos, es referente obligado en la segunda de las etapas del autor de Inteligencia sentiente; la relación entre ambos autores es compleja, al tiempo que, aunque Zubiri no cita explícitamente a Heidegger en demasiadas ocasiones, sí parece tenerlo en cuenta en otros muchos lugares. Sin embargo, a pesar de la preocupación zubiriana por comprender, incluso traducir, la obra del pensador alemán, no podemos olvidar, tal como nos recuerda Pintor, que esta recurrencia a Heidegger es siempre al mismo tiempo una discusión de su obra, que le permite avanzar en un proceso de maduración intelectual, para

\footnotetext{
${ }^{14}$ Zubiri 1993, p. 11.

${ }^{15}$ Cfr. ibídem, pp. 17-18.

${ }^{16}$ Pintor 1992, p. 90

${ }^{17}$ Cfr. ibídem, pp. 91-92.
} 
posteriormente dejar atrás al propio Heidegger. ${ }^{18} \mathrm{Al}$ pasar la fenomenología por el tamiz heideggeriano, Zubiri constata que la conciencia no es punto de partida absoluto; es más, la conciencia no es factible sin algo previo, un ámbito de contacto con la realidad previa a ella.

Para Zubiri ya en los años treinta la conciencia, y las operaciones de conceptualización lógica que en ella se dan, son secundarias respecto a la realidad sentida, que es así fundamento de toda verdad real. El problema radical de la filosofía no es el de la verdad real, sino, más radicalmente, el de la realidad misma, esto es, la determinación formal de lo que entendamos por realidad. Más de un lector pensará, y no le faltará cierta razón, que esta afirmación lanzada por Zubiri no se encuentra ni mucho menos desgajada de la idea heideggeriana de aletheia, en la cual la verdad lógica se funda. Sin embargo, el paralelismo no desdice de la originalidad de Zubiri, al tiempo que nos permite comprobar más concretamente por dónde se decantó la actitud de Zubiri. ${ }^{19}$

Zubiri acompaña, así, en parte la crítica heideggeriana a la fenomenología tal como Husserl la entiende, o más concretamente al empeño de éste por centrar todo su esfuerzo filosófico en la originalidad de la conciencia. En efecto, el hombre, ser en el mundo, trata la realidad habiéndoselas con ella, y esto es algo anterior a la reflexión sobre la realidad. Sin embargo, Zubiri se separa del intento fenomenológico heideggeriano en un punto crucial: éste centra toda la especulación filosófica en el ser, lo que para Zubiri es, evidentemente, inaceptable. Cierto es que el rechazo a dicha centralidad del ser es paulatino, pero es uno de los aspectos centrales de la obra zubiriana madura. ${ }^{20}$ Sin embargo, el poso que la fenomenología deja en la obra madura zubiriana es de gran importancia; no como "filosofía", sino como "horizonte filosófico”.

\subsection{La coherencia con la ciencia}

Del mismo modo que la fenomenología forma parte del sustrato inicial de la metafísica en Zubiri, así lo hace su preocupación por llevar a cabo una especulación que en todo momento sea coherente con el conocimiento científico de nuestros días, que de la mano de la ciencia afronte el problema radical de

${ }^{18}$ Cfr. ibídem, p. 92

${ }^{19}$ Cfr. ibídem, p. 94

${ }^{20}$ Cfr. ibídem, pp. 98-100 
la metafísica: la realidad misma. No descubrimos, a estas alturas de nuestra exposición, nada nuevo al lector, pero quizá resulte interesante apuntalar esta idea básica que ha venido insinuándose a veces, explicitándose en otras ocasiones: para Zubiri la filosofía no sólo no ha de dar la espalda nunca al saber científico, sino que ha de ser enteramente congruente con él. Zubiri percibe a lo largo de su periplo filosófico la gran importancia que la ciencia moderna tiene en nuestra cultura, hasta el punto de equipararla en su trascendencia a la metafísica griega, el derecho romano y la religión de Israel; sin embargo, en ella se puede observar un cierto estado de desconcierto, que, en su opinión, tiene una triple raíz: la confusión en la ciencia, la desorientación en el mundo y el descontento íntimo consigo misma. Es importante acompañar a Zubiri en el análisis de esa confusión, ya que seguramente nos permitirá vislumbrar con ecuanimidad tanto la ciencia como la actividad intelectual en su conjunto. ${ }^{21}$

La confusión de la ciencia va más allá de la confusión de alguna de las ciencias en sus fundamentos, pues es una crisis de principios, en la que se ha olvidado que "una ciencia es, en efecto, realmente ciencia, y no simplemente una colección de conocimientos, en la medida en que se nutre formalmente de sus principios, y en la medida en que, desde cada uno de sus resultados, vuelve a aquéllos" (ibídem, p. 30). Así, nos encontramos, dirá Zubiri, con que las ciencias aparecen desdibujadas, esto es, carecen de perfiles de existencia marcados; se está confundiendo cualquier conjunto de conocimientos homogéneos con ciencia; no se sabe dónde comienza y termina una ciencia. Conjuntamente nos encontramos con otra terrible confusión: todas las ciencias se presentan en un mismo plano, resultando así que, además de carecer de unidad sistemática, las ciencias carecen de perspectiva. Se ha dado a todos los saberes el mismo rango, al ser catalogados todos de "científicos", con lo que se supone, paralelamente, que todas las ciencias son equivalentes, al ser todas ellas "positivas", obviando que quizá ( como de hecho sucederá realmente) no es posible dar a todas las ciencias el mismo grado de positivización. ${ }^{22}$ La desorientación en el mundo viene dada por la carencia de un lugar propio en éste de la función intelectual, ya que "esta función se ha convertido en una especie de secreción de verdades, vengan de donde vinieren y versen sobre lo que versasen. Ante este diluvio de conocimientos positivos, el mundo comienza a

${ }^{21}$ Zubiri 1989, p. 29.

${ }^{22}$ Cfr. ibídem, p. 31 
realizar una peligrosa criba de verdades, fundada precisamente sobre el presunto interés que ofrecen, interés que se torna pronto en una utilidad inmediata. La función intelectual se mide tan sólo por su utilidad, y se tiende a eliminar el resto como simple curiosidad" (ibídem, p. 32).

Por último, el científico se encuentra descontento consigo mismo, en buena medida por la exuberancia de sus saberes: el científico se percata de que sus métodos tienen poco que ver con su inteligencia; el científico comienza a estar harto de saberes. La ciencia nació en una vida intelectual, mientras que parece que para el científico de hoy en día se da una desvinculación entre ciencia y vida intelectual. ${ }^{23}$ Toda esta incertidumbre se ha volcado también sobre la filosofía, seguramente de manera más desproporcionada aún. Para recuperar ambas, dentro de la vida intelectual, es preciso revitalizar la conexión que existe entre ciencia y verdad.

El fin último de toda ciencia es la verdad, esto es, "la posesión intelectual de la índole de las cosas. Las cosas están propuestas al hombre y la verdad no consiste sino en que la inteligencia revista la forma misma de aquéllas" " (ibídem, p. 37). Esta visión de la verdad parte de un hecho bastante claro, al menos para Zubiri: las cosas están "pro-puestas" a la inteligencia. Por lo tanto, el primer paso para llegar a la verdad es atenerse a las cosas; es un paso primero, indispensable, pero que no agota en sí el acceso a la verdad: la verdad supone una cierta manera de preguntarse por las cosas, es decir, supone un modo concreto de preguntarnos genéricamente por ellas: la verdad presupone un sistema de cuestiones previas con que la inteligencia afronta la realidad. ${ }^{24}$

Ese sistema de preguntas no surge al azar, ni de forma ahistórica, sino que surge inserto en una tradición determinada, de suerte que "en su situación concreta el hombre esboza un proyecto, un modo de acercarse a las cosas e interrogarlas, y sólo entonces dan éstas la respuesta en que se constituye el acuerdo con ellas: la verdad" (ibídem, p. 41).

Ahora bien: una inadecuada comprensión de la ciencia puede acarrear desviaciones serias en su estructura intelectual. Tal es el caso en tres grandes corrientes del pensamiento moderno: el positivismo, el pragmatismo y el historicismo.

${ }^{23}$ Cfr. ibídem, p. 33

${ }^{24}$ Cfr. ibídem, p. 40. 
Para el positivismo la ciencia ha de preocuparse por los "hechos". Estos, a su vez, quedan fácilmente reducidos a datos empíricos, de suerte que la verdad científica es un acuerdo con estos datos, y la ciencia misma no es sino un saber sobre la concatenación ordenada de hechos. ${ }^{25}$

En el caso del pragmatismo, se parte de la idea de que la ciencia, por encima de todo, necesita saber interrogar a las cosas, necesidad dada por el interés por hallar una conexión, un orden inteligible en los datos que la experiencia va proporcionando, de modo que la verdad es una necesidad: el hombre necesita, para no encontrarse perdido entre las cosas, saber cómo van a ir ocurriendo; la ciencia reduce los datos sensibles, tan vastamente variados, a una serie de relaciones sencillas que permiten prever el curso de los fenómenos. Ciencia no es, por lo tanto, sólo visión de la realidad, sino también pre-visión, por medio de leyes verdaderas. ${ }^{26}$

El historicismo da gran valor al hecho de que la ciencia se encuentra inserta siempre en una determinada cultura; si cultura es el producto de la realidad histórica, la ciencia no deja de ser una forma de un determinado estado cultural, al tiempo que la verdad es el valor de la inteligencia. ${ }^{27}$

Esas posturas se encuentran erradas en su misma raíz, debido a que en buena medida han perdido la genuina esencia de la ciencia, que tiene una clara demarcación:

Si se considera la ciencia como una penetración cada vez más honda y más extensa en un mundo de objetos en que constitutivamente estamos inmersos, todo cambia súbitamente de aspecto: el positum no es una mera impresión sensible; la simplicidad en el manejo de los fenómenos no es una ciega utilidad biológica; la situación histórica en que nos hallamos colocados no es una mera forma objetiva del espíritu. En cualquiera de estos tres aspectos, el pensamiento y el hombre no pueden concebirse ni entenderse si no es en y con las cosas. (...) La ciencia no es una simple adición de verdades que el hombre posee, sino el despliegue de una inteligencia poseída por la verdad. Entonces las ciencias ya no se hallan meramente yuxtapuestas, sino que se exigen mutuamente para captar diversas facetas y planos de diversa profundidad, de un mismo objeto real. La vida intelectual es un constante esfuerzo por mantenerse en esta unidad primera e integra” (ibídem, p. 48).

${ }^{25}$ Cfr. ibídem, pp. 41-43.

${ }^{26}$ Cfr. ibídem, p. 43.

${ }^{27}$ Cfr. ibídem, p. 44. 
He ahí el auténtico sentido de la ciencia en nuestra vida intelectual, y he ahí el referente que Zubiri desea tomar de la filosofía respecto de la ciencia. A partir de esta afirmación, Zubiri profundiza en el significado del entroncamiento entre filosofía y ciencia a la búsqueda de un objetivo común: el esfuerzo por la realidad. Sin embargo, no pensemos que ciencia y filosofía se preocupan por igual de lo real. La ciencia, con todas sus posibles ramificaciones, no deja de fijarse tan sólo en el orden talitativo de las cosas reales, mientras que será función de la filosofía, de la metafísica, centrarse en el orden trascendental de la realidad. El orden trascendental no se construye a espaldas del talitativo, pero, como es evidente, supone una dimensión radicalmente distinta en el estudio de lo real.

En efecto, como el mismo Zubiri nos dice, "ciertamente, renunciar a lo que la ciencia dice de la realidad de las cosas, sería renunciar a algo que hoy por hoy es muy justamente admitido como una conquista definitiva. Es menester afirmarlo muy enérgicamente. Pero esto no toca al problema que estamos tratando. Más aún, puede decirse que la ciencia ni tan siquiera se ha planteado este problema nuestro". ${ }^{28}$ Dicho problema se centra en Zubiri, en buena medida, a partir de una constatación que hace sobre las cualidades sensibles: parece que la realidad de éstas puede estar en contradicción con la ciencia moderna; de este modo, dichas cualidades sensibles son meras impresiones subjetivas. Negar esto supone caer en un "realismo ingenuo"; aceptarlo, nos conduce indefectiblemente a un "realismo crítico". ${ }^{29}$ Sin embargo, ni realismo ingenuo ni realismo crítico suponen para Zubiri una respuesta admisible.

Intelección y metafísica

\subsection{El hombre y la intelección de lo real}

El hombre es el único animal que tiene como nota la inteligencia, una inteligencia sentiente. Sin embargo, inteligir no es la única actividad que lleva a cabo el hombre. La sustantividad humana no sólo se encuentra inmersa en la realidad, sino que se enfrenta a la realidad, se comporta con las cosas como reales. Esta acción, nos indica Zubiri, se hace a través de tres momentos, la int-

${ }^{28}$ Zubiri 1986, p. 150.

29 “Aceptando esta concepción científica, la filosofía ha pensado que estas impresiones subjetivas nuestras quedan referidas a la realidad tan sólo por un razonamiento causal: lo real sería la causa de nuestras impresiones subjetivas. Fue la idea expresamente enjuiciada por el propio Kant”, Zubiri 1980, p. 171 
elección, la volición y el sentimiento. ${ }^{30}$ Esos momentos no son más que eso, momentos; no se trata de que el hombre lleve a cabo tres tipos de acciones diferentes, ya que la sustantividad humana actúa "a una" como sistema en todas las actividades que realiza; hay predominancias de unas notas sobre otras en la actividad única de la estructura sustantiva humana, pero siempre se actúa como sistema ante la realidad.

El sistema de la acción humana es único, y se muestra siempre como unidad; es una unicidad de acción que va más allá de los actos de inteligencia, voluntad o sentimiento, que afecta, por tanto, a todos los aspectos constitutivos de la sustantividad humana, incluyendo las mismas notas fisicoquímicas. De este modo, la unicidad en la sustantividad humana "significa que los diferentes aspectos de toda acción del hombre no son sino eso: aspectos de una acción una y única. Digerir, andar, pensar, etc., no son sino aspectos de una acción única: la de ejecutarse como hombre, como animal de realidades" (ibídem). No cabe duda de que esta nueva lectura de la realidad humana va ligada a una perspectiva que rompe por completo con la idea de sustancia: frente a la idea que la filosofía ha tenido a lo largo de toda su historia, esto es, que inteligencia, voluntad, etc., son notas "que brotan de la sustancia como las ramas de un tronco". ${ }^{31}$

Para Zubiri, la realidad humana es un sistema en el que cada una de sus acciones no es ajena a todas las demás; se plantea la realidad humana como una sustantividad con unidad de sistema. ${ }^{32}$ De entre todas las notas que caracterizan al sistema sustantivo que es el hombre apunta una con rasgos peculiares, la inteligencia, hasta el punto de que es la nota que principalmente define al hombre: el hombre es una inteligencia sentiente. En efecto, el hombre es persona, y lo es precisamente por ser inteligencia sentiente, "cuyo acto formal es impresión de realidad”. ${ }^{33}$ La intelección es la mera actualización

\footnotetext{
30 "La aprehensión de intelección sentiente, la volición tendente, el sentimiento afectante, no son sino tres momentos de una acción única: la acción de comportarse con las cosas como reales”, Zubiri 1985, p. 72.

${ }^{31}$ Zubiri 1986, p. 73.

${ }^{32}$ En el caso de concebir al hombre como sustancia "cada una (de sus notas) tiene su acción propia, según sus internas propiedades, y a lo sumo la acción de una nota puede influir sobre la acción de las demás por el hecho de pertenecer al mismo sujeto. Pero, a mi modo de ver, esto es falso, porque no sólo no hay una sustancia que fuera raíz de las notas, sino porque sólo hay una sustantividad cuya unidad es la unidad del sistema”, ibídem

${ }^{33}$ Zubiri 1984, p. 81
} 
en la inteligencia sentiente de lo que se aprehende "de suyo", de lo que se aprehende realmente; la realidad, por tanto, es el apoyo constitutivo del hombre para que éste sea persona. La realidad es el ámbito en que se encuentra inmerso el hombre, el hombre está en la realidad, no sólo entre otras cosas reales, de modo que el carácter de realidad en las acciones es su apoyo para ser persona.

Todo lo indicado hasta el momento puede servirnos para darnos una pista que nos ayude a comprender hasta qué punto es imprescindible el estudio de la inteligencia sentiente en la realidad humana. Más adelante veremos más precisivamente en qué consiste la sustantividad humana, pero tengamos en cuenta el papel primordial que el ella desempeña la inteligencia sentiente. Intelección sentiente, por tanto, es nota de la realidad sustantiva que llamamos "hombre". Pero también es modo de aprehender realmente la realidad, de modo que las notas de lo real se nos presentan como realidades, no como estímulos. Esta es la faceta del problema de la intelección que vamos a tratar ahora.

En efecto, en el hombre encontramos que el contenido de los estímulos que recibe no es formalmente signo de respuesta, ya que en virtud de su hiperformalización abre la clausura de los estímulos hacia una nueva formalidad no estimúlica, transformándose la signitividad en la presencia de algo "en propio"; 34 es una nueva formalidad en la que ya no tenemos independencia objetiva sino reidad: el estímulo pasa de ser de "nota-estímulo" a ser "nota-real". El hombre es un animal "hiper-signitivo", de suerte que necesita aprehender los estímulos no como signos objetivos sino como realidades: "el animal hiperformalizado no es viable sin aprehensión de realidad". ${ }^{35}$ En consecuencia, "para dar sus respuestas adecuadas, el hombre no puede limitarse a 'seleccionarlas' biológicamente, sino que tiene que 'elegirlas' en función de la realidad. El hombre elige intelectivamente su respuesta. Elegir es determinar una respuesta en la realidad y según la realidad" (ibídem, p. 73). ${ }^{36}$

\footnotetext{
${ }^{34}$ Hiperformalización es el paso de la independencia objetiva a la reidad", Zubiri 1980, p. 61

${ }^{35}$ Zubiri 1984, p. 72

${ }^{36}$ Todo este proceso, todo ese modo de enfrentarse a la realidad, es estructural, basado en el principio estructural de la hiperformalización: "La hiperformalización no es un fenómeno de conducta adaptativa, sino de un principio estructural”, ibídem.
} 
Hay que tener muy en cuenta, para comprender la postura de Zubiri, cuán diferentes son las formalidades de estimulidad y de realidad. Son, como decimos, dos formalidades diferentes, radicalmente diferentes, y cuya distinción es esencial y no gradual. Una complicación de estímulos sólo será siempre signo de respuesta, independientemente de su grado de formalización y en tanto no se alcance la hiperformalización; nunca será algo "en propio", "de suyo", nunca será formalmente realidad. Realidad y signitividad son formalidades diferentes, por lo que aprehender realidad es muy distinto de aprehender signos: es una formalidad exclusiva de la inteligencia, al tiempo que aprehender algo como real es el acto elemental de la inteligencia; es más, como afirma enfáticamente Zubiri, "la realidad no es sólo un acto exclusivo y elemental de la inteligencia, sino que es su acto radical” " (ibídem, p. 77), lo que permite hablar de realidad como "formalidad de reidad impresivamente aprehendida en intelección sentiente" “ (ibídem, p. 173), definición de realidad como vemos bastante novedosa, ajena a las ideas de realidad que se han tenido en los diversos tipos de realismo, en los que la realidad venía siempre definida como una zona de cosas. ${ }^{37}$

La determinación de la intelección como intelección sentiente supone una nueva forma de entender la realidad, radicalmente distinta a las que se ha venido manejando tradicionalmente en la historia de la filosofía: existencia, ser, objetualidad...; para Zubiri, y de manera coherente con la concepción de la intelección como inteligencia sentiente, la realidad es el carácter de "de suyo".

En efecto, el acto formal y propio de la intelección no es concebir (esto sería lo propio de una inteligencia concipiente, que es como tradicionalmente ha venido siendo considerada la intelección), sino inteligir sentientemente la realidad: en el hombre, la formalidad propia de lo inteligido qua inteligido es realidad, lo primero que intelige el hombre es la realidad, de modo que el acto primario de la inteligencia no es concebir, sino aprehender la cosa en su formalidad real.

La realidad es el carácter de "de suyo", y no otra cosa. Ahora bien, ese carácter de "de suyo", determinación básica de la realidad, es el carácter primario

37 "Realidad es formalidad de realidad impresivamente aprehendida en intelección sentiente. No es lo que por realidad han entenedido los realismos tanto ingenuos como críticos, a saber, una determinada zona de cosas", ibídem, p. 173. 
de las cosas como cosas reales, al tiempo que es lo primario en la intelección. Así es como resulta de capital importancia establecer un vínculo entre la intelección y las cosas reales, pero partiendo de la intelección misma. Porque de la noción de inteligencia sentiente pende el modo en que se articula formalmente la de sustantividad: la realidad es el "de suyo", carácter que sólo puede ser aprehendido sentientemente, y que siempre tiene una estructura sustantiva, esto es, una estructura como sistema de notas cíclico con suficiencia constitucional. Y en esto consiste la realidad, en ser formalidad de realidad, ser formalmente "de suyo", y no "ser" sin más. Por lo tanto, en el caso de la inteligencia sentiente, lo sentido en impresión nos instala en la realidad misma de lo aprehendido, quedando abierto ante el hombre el camino de la realidad en y por sí misma; en el hombre lo que se da es una autonomización de las notas en la que éstas no son signos, sino realidades autónomas, esto es, gracias a su hiperformalización, en el hombre hay alteridad de realidad, no autonomía de signitividad (ibídem, p. 63). ${ }^{38}$

Como vemos, realidad es siempre formalidad. La formalidad es un modo de alteridad del "de suyo", es formalidad de alteridad del "de suyo" a diferencia del modo de actualidad de la mera estimulidad. Es en virtud de esta afirmación como se puede comprender la afirmación de Zubiri de que "este 'de suyo' no significa tan sólo el hecho de la existencia, sino que significa que lo que un clásico entendería tanto por esencia como por existencia pertenecen 'de suyo' a la cosa. Realidad no es formalmente sinónimo ni de existencia ni de esencia, aunque nada sea real sin ser existente y sin ser esenciado".

\subsection{Modalización de la intelección.}

El hombre se encuentra entre las cosas reales inteligiéndolas, aprehendiéndolas sentientemente. Ahora bien, y tal como hemos visto anteriormente, esa intelección tiene momentos diferentes: la aprehensión primordial, el logos y la razón. Todos ellos son intelección, y en cada uno de ellos, aunque se aprehende el mismo carácter de "de suyo", se hace con matizaciones que varían de uno a otro:

\footnotetext{
${ }^{38}$ También conviene recordar otras palabras de Zubiri algunas páginas antes: "el calor aprehendido ahora [con los caracteres que le pertenecen en propio] no consiste formalmene en ser un signo de respuesta, sino en ser caliente 'de suyo'. Pues bien, esto es lo que constituye la realidad. Esta es la nueva formalidad: formalidad de realidad o reidad”, ibídem, p. 57
} 
a) En aprehensión primordial lo que aprehendemos es realidad: "esta" cosa, "este" color. Lo aprehendido es la realidad inmediatamente dada en la aprehensión, es el "de suyo" primordial.

b) En el logos, aprehendemos la cosa en realidad: la realidad se intelige en la afirmación; cada cosa se aprehende dentro del campo de realidad entre otras cosas. El logos no se refiere a "este" color, sino que afirma: este color es verde. El "de suyo" es campal.

c) En la razón se aprehende en la realidad: la realidad es una realidad construida, inteligida en el mundo; para la razón: este color (que es verde) es un fotón. El "de suyo" es mundanal.

Esta triple determinación de las cosas reales como "realidad", "en realidad" y "en la realidad" incide en el carácter de "de suyo", pero no lo exceden. No se aprehende más que lo que las cosas "de suyo" son, independientemente de que sean aprehendidas primordial, campal o mundanalmente.

Ese carácter de "de suyo" tiene una estructura sustantiva, no un carácter sustancial. Es fácil ver esa estructura sustantiva de la realidad tanto en la aprehensión primordial como en la campal; puede, quizás, que en principio no parezca tan claro al referirnos a la razón, ya que ésta busca el fundamento. Sin embargo en la razón el carácter de "de suyo" de las cosas reales permanece, teniendo la misma estructura sustantiva que en la aprehensión primordial y que en el logos: la razón busca un fundamento, pero ese fundamento no puede ser entendido de otra forma que como un modo del "de suyo". Siempre que se piensa la realidad, se hace como sistema de notas, como estructura sustantiva.

Lo que se hace en todo momento es inteligir, esto es, aprehender lo real como real. En este proceso la realidad tiene una doble función, ya que "por un lado designa el objeto formal propio del inteligir, (...) pero por otro lado, realidad designa también la índole estructural del acto mismo de inteligir, a saber, esa especie de versión de la intelección a lo real". ${ }^{39}$

Por tanto, realidad es objeto formal de la intelección al tiempo que la intelección formalmente consiste en ser aprehensión de lo real como real.

${ }^{39}$ Zubiri 1980, p. 250 
En la perspectiva de la inteligencia sentiente, el modo primordial de intelección es la aprehensión primordial de realidad, que en buena medida es la que se ha tenido en mente en lo indicado hasta el momento. Sin embargo, para reflexionar con más precisión sobre la vinculación sustantividad-inteligencia, es menester volver nuestra mirada hacia los otros dos momentos estructurales de la intelección, el del logos y el de la razón, para completar así adecuadamente nuestra investigación. Para ello, debemos comenzar refiriéndonos al "campo de realidad". La perspectiva campal, la concepción campal de la realidad, es fundamental en la filosofía de Zubiri. Bástenos para comprender esto la metáfora que al respecto el propio Zubiri hace:

comparando el campo a la luz, diremos que la cosa real es ante todo fuente de luz: es luminosa, es lo que la constituye en luminaria (...) Si consideramos la luz como algo que ilumina las cosas reales, entonces esta luz ya no es una mera nota de cada cosa, sino que es un ámbito que abarca a todas las cosas comprendidas en el ámbito de iluminación, incluyendo en este ámbito la propia fuente luminosa. ${ }^{40}$

Como vemos, esta metáfora nos remite al carácter respectivo de todas las cosas reales, a la remitencia intrínseca de cada cosa real a todas las demás por el hecho de ser real. En la dimensión campal se describe la funcionalidad de lo real; hay una unidad de los momentos de individualidad y del campal en el "entre" funcional. ${ }^{41}$ Cada cosa está "entre" las demás, en virtud de la funcionalidad de lo real, por lo que el modo de inclusión campal de cada cosa real es intrínseca y formalmente funcional. La funcionalidad no es relación, ${ }^{42}$ sino que es el carácter estructural del campo mismo en cuanto campo, de suerte que "unas cosas dependen de otras porque todas están incluidas en un campo que es intrínseca y formalmente campo funcional. Lo cual significa que toda cosa real, por su momento de campalidad es realidad funcional". ${ }^{43}$

Esa funcionalidad se articula, a su vez, de un modo muy preciso: cada cosa real lo es por ser formalmente "de suyo". Si consideramos la cosa real desde un punto de vista trascendental, veremos que cada cosa real es trascendentalmente "de suyo" abierta, en una dimensión a la que Zubiri denomina precisa-

${ }^{40}$ Zubiri 1982, pp. $19-20$

${ }^{41}$ La funcionalidad, recordemos, no es relación causal, sino que es dependencia en el sentido más lato del vocablo. Por lo tanto, hay multitud de formas darse la funcionalidad: la sucesión, la coexistencia, la espacialidad, la espaciosidad,... it Cfr. ibídem, 36-37

42 “Esta funcionalidad es dependencia en el sentido más lato del vocablo", Zubiri 1980, p. 37.

${ }^{43}$ Zubiri 1982, p. 38. 
mente "funcional". La actualización campal funcional se nos presenta como la propia de la unidad de todos los modos de realidad sentida; entre estos modos hay uno que define más concretamente la funcionalidad de lo real en el campo, el "hacia": lo campal es funcional en "hacia". ${ }^{4}$

En virtud de esa funcionalidad "hacia" de todo lo real, nos encontramos en el momento de la intelección en el cual aprehendemos lo que las cosas son "en" realidad; nos encontramos en la perspectiva de la intelección como logos. El logos tiene una problemática propia, pero que resulta de gran importancia en la concepción sustantiva de la realidad: la problemática del juicio.

Paralelamente, la razón muestra sus propias peculiaridades. Es dentro de la perspectiva de la razón como el problema de lo real cobra un nuevo planteamiento: el problema de la realidad como fundamento, no como nuda realidad. ${ }^{45}$ La realidad como fundamento no se da en "la" realidad como si fuera un objeto, ya que "principio" (que es a lo que remite la noción de "fundamento") no es algo oculto en lo principiado. La pregunta por el fundamento en "la" realidad ha de llevarnos a un momento intrínseco de ella, no a un momento añadido: "el fundamento es realidad, pero realidad cuya carácter de realidad consiste justamente en fundamentar realmente" (ibídem).

De este modo, la realidad nos "dará que pensar"; la realidad en cuanto tal es lo que da que pensar, al tiempo que el dar que pensar constituye a la realidad en principio de intelección. La realidad nunca deja de ser, se considere como se considere, formalidad del "de suyo", formalidad que es, desde el punto de vista de la intelección, el modo de alteridad del "de suyo", no modo de alteridad de mera estimulidad.

\subsection{Aprehensión primordial y sustantividad}

Ya hemos indicado con anterioridad qué entiende Zubiri por aprehensión primordial de realidad; no vamos a repetirlo ahora. Lo que haremos será fijarnos más precisivamente en algunos aspectos que redundan, desde la aprehensión primordial misma, en el modo en que se ha de entender la estructura sustantiva de la realidad.

${ }^{44} C f$ r. íbidem.

${ }^{45}$ En efecto, la problemática de lo real se remite, en la razón, a una nueva dimensión: "La realidad no es ahora nuda realidad sino realidad fundamentante". Es así como nuestra primera pregunta a dilucidar será “¿cómo está dada esta realidad en cuanto fundamentante?” (Zubiri 1983, p. 47). 
En primer lugar, es preciso indicar que parece claro que en Zubiri la aprehensión de la realidad supone una ruptura tajante con la concepción de las notas como "estímulos". ${ }^{46} \mathrm{Al}$ hablar de "estímulo" frente a "formal realidad", Zubiri no piensa que el primero sea "irreal" en el sentido de que no exista; pero tampoco es realidad formalmente dicha. Lo que ocurre es que "el estímulo es justamente arreal. La realidad, en cambio, se nos presenta como algo más que estímulo. El propio estímulo se nos presenta como realidad estimulante, es decir, como algo que emerge de aquello que nos está estimulando y que le pertenece en propio en aquello que nos estimula” (ibídem). Así, el momento de realidad radicará en ser el mencionado "en propio", el "de suyo".

Ese momento de "de suyo" existe tan sólo para el hombre, aunque el hombre perciba las "mismas" cosas que cualquier otro animal. Vayamos por partes; para cualquier animal, éste aprehende ciertas notas, que podríamos llamar notas elementales, a través de un proceso de "sensación". Esas notas, al estar formalizadas en la sensación son independientes, son autónomas, tanto respecto del sentiente como respecto de otras notas: es la formalización la que constituirá la "unidad" de todo el contenido sentido, de suerte que las notas se presentan con una cierta clausura. A partir de esta afirmación, comprenderemos la diferencia entre el hombre y el resto de los animales: esas unidades "pueden tomar el carácter de unidades autónomas. Son entonces constelaciones autónomas. Su aprehensión ya no es simple sensación; es percepción. (...) Las mismas notas elementales pueden constituir distintas constelaciones perceptivas, es decir distintos tipos de contenido unitario, según sea la índole del animal". ${ }^{47}$

Entre esos tipos de contenido unitario se singulariza, evidentemente, el que confiere la inteligencia sentiente a esas constelaciones de notas, ya que las aprehende como realidad. Y es el único animal que lo hace.

La intelección sentiente es un modo de enfrentarse a lo real radicalmente distinto a cualquier otro, al aprehender las cosas tal como son "de suyo". Pensemos en el caso del calor: cuando afirmamos que "el calor calienta", o, mejor dicho, cuando aprehendemos que "el calor calienta", el calor aquí aprehendido es distinto del aprehensor, "pero en su distinción misma este calor calen-

46 "He pensado que para entender lo que es la realidad hay que contraponerla a cierta presencia de las cosas en la cual éstas no se presentan formalmente como realidades sino como estímulos”. EDR, p. 29. ${ }^{47}$ Zubiri 1980, p. 37 
tante pertenece formalmente al aprehensor: es distinción en y para el proceso sentiente (...). En el nuevo modo de aprehensión se aprehende el calor como nota cuyos caracteres térmicos le pertenecen 'en propio'" (ibídem, p. 55).

Así, toda propiedad es propia de algo, le pertenece en propio; en el caso del calor, ejemplo propuesto por Zubiri "no se trata de que los caracteres sean 'propiedades' del calor, sino de que esos caracteres le pertenezcan en propio, y no de que sean caracteres de un sujeto llamado calor (lo cual no es algo primitivamente dado), sino de que sean el 'propio calor' mismo" (ibídem).

No podemos olvidar, por otra parte, el ya tantas veces invocado vínculo radical que se establece entre inteligir y sentir en la filosofía de Zubiri. El sentir humano es siempre un sentir intelectivo, por lo que el hombre siente cualidades sensibles, pero en su formalidad de realidad. Sentir es básicamente impresión de realidad. La realidad, por lo tanto, no es una construcción subjetiva, no es algo inferido o concebido: es algo impresivamente dado en estricta formalidad, es, en definitiva, el "de suyo", y, por lo tanto, es algo físico. ${ }^{48}$

Logos y sustantividad

El logos, evidentemente, se ha de entender como logos sentiente; en él podemos encontrar dos momentos: el individual y el campal. Estos dos momentos se dan compactamente en la aprehensión primordial. Sin embargo, en la intelección como logos quedan autonomizados. Esto se debe precisamente a que el logos aprehende cada cosa real entre y desde otras cosas reales, es decir, aprehende campalmente. La aprehensión campal se funda en la respectividad de lo real. La respectividad puede afectar a la cosa real cualitativamente, determinando lo que ésta es dentro del campo; es respectividad campal. Puede afectar a la cosa trascendentalmente, determinando lo que la cosa es como momento del mundo; es respectividad mundanal. En ambos casos, la intelección de una cosa real como respectiva a otras es lo que Zubiri denomina la intelección de lo que la cosa es "en realidad".

En el ámbito de la intelección como logos, nos encontramos con la apertura de suidad: es la apertura de la cosa aprehendida como real a otras cosas reales también aprehendidas, de modo que "cuando una cosa real está actualizada respectivamente a otras cosas reales en esta línea de la apertura, decimos que la cosa se halla en un campo de realidad. Inteligir lo que una cosa real es

${ }^{48}$ Cfr. íbidem, pp. 321-322 
en realidad es ahora inteligirla como momento del campo de realidad: como siendo respectiva a otras cosas del campo" (ibídem, p. 269).

Es así como en el ámbito del logos tiene cabida el juicio, cuyo máximo exponente es el juicio predicativo, en el que se afirma que "A es B". En el juicio, lo único que se hace es catalogar talitativamente lo aprehendido entre otras cosas del campo de realidad: se afirma que esto es tal cosa, pero en una aproximación meramente denominativa.

\subsection{Razón y sustantividad}

Además de con la apertura campal, la realidad se encuentra ante otro tipo de apertura, la mundanal, como muy bien nos recuerda Zubiri:

Pero la formalidad de realidad está respectivamente abierta también en otra línea. Por ser pura y simple realidad, está trascendentalmente abierta a ser momento de 'la' realidad. Está, pues, abierta a lo que hemos llamado mundo. Entonces inteligir lo que una cosa real es en realidad, es inteligirla como momento del mundo " (ibídem, p. 269).

En esta nueva apertura cobra sentido la distinción entre realidad y ser. Realidad, digámoslo una vez más, es formalidad de lo real como real, lo real como algo "de suyo", mientras que ser es actualidad de lo real en su respectividad como real, actualidad en el mundo. Realidad y ser no son la misma cosa; existen múltiples modos propios de ser que no son modos propios de realidad, al tiempo que el ser se funda en la realidad, tiene su razón en ella. "No hay un esse reale, sino tan sólo realitas in essendo. El principio de la razón en cuanto tal es, pues, no el ser sino la realidad. Por esto es rigurosamente falso pensar que el ser sea la última instancia de las cosas. La última instancia de las cosas reales es "realidad"' (ibídem).

La raíz del error de concebir el "ser" como "principio" se encuentra en una equivocada e inveterada concepción de la inteligencia: la inteligencia como inteligencia concipiente. "Principio" ha de ser entendido no en intelección concipiente, sino en intelección sentiente. La limitación de la intelección concipiente radica en que usa para plasmarse de juicios: el juicio es sólo un modo de actualización, no el único, pero que en la logificación de la intelección, constante a lo largo de toda la historia de la filosofía, hace concebir la razón como facultad de principios. Esta visión errónea de la intelección ha ido evolu- 
cionando a lo largo de dicha historia de la filosofía, ya sea como rigor lógico (así la entendieron los griegos), ya sea como organización de la experiencia (la idea de Kant), ya sea como necesidad dialéctica (así la veía Hegel). ${ }^{49}$ Todas ellas, como todas las demás que se han dado en el itinerario histórico de la filosofía, son erróneas, concluirá Zubiri, al no concebir la intelección como intelección sentiente. ${ }^{50}$ Es precisamente a partir de la noción de inteligencia sentiente como podemos llegar a una idea adecuada de lo que es realmente la razón, esto es, como intelección principial.

Las cosas reales nos dan que pensar, pero nos dan que pensar en su realidad. Así, las cosas reales han de estarnos ya presentes como reales. Zubiri dirá a este respecto que las cosas reales nos darán que pensar porque ya están inteligidas como reales. ${ }^{51}$ En consecuencia, la razón como modo de intelección de lo que las cosas nos dan que pensar será un modo de intelección previa de lo real; la razón tiene su origen en las cosas, pero en las cosas ya previamente inteligidas como reales.

Pudiera parecer de escasa importancia la distinción que se establece entre lo que las cosas son "en realidad" y lo que son en "la" realidad; sin embargo, se trata de una distinción bastante significativa:

Lo más radical de la intelección es, evidentemente, la aprehensión primordial. En ella la cosa real se impone como sistema de notas; sin embargo, la aprehensión primordial no es exhaustiva, y precisa de esas dos ulteriores modalizaciones para hacerse más completa, de modo que se pueda aprehender lo que las cosas son, tanto talitativa como trascendentalmente. Esa es, respectivamente, la función del logos y de la razón.

El logos tiene una función meramente denominativa, como indica Ferraz; clarifica y organiza las cosas reales, que no aprehendemos aisladamente, sino entre otras, dentro de un campo de realidad. Decimos lo que las cosas son, pero tan sólo desde un punto de vista definitorio, talitativo. No salimos de la inmediatez. Así, por ejemplo, si aprehendemos algo con las notas: ser vivo, que ladra, con cuatro patas, ..., diremos "esto es un perro".

\footnotetext{
${ }^{49}$ It Cfr. Zubiri 1982, pp. 68-69

${ }^{50}$ Cfr. ibídem, p. 67

${ }^{51}$ No puede ser de otra forma, ya que "la mera actualidad intelectiva de lo real como real es la intelección”, ibídem, p. 82. Sólo en virtud del proceso de la intelección, pues, se puede afirmar que las cosas nos den que pensar.
} 
El caso de la razón es bien distinto, ya que afirma lo que la cosa es como momento del mundo; va allende lo inmediato buscando el fundamento; no significa esto que se remita a algo diferente a lo que las cosas de suyo son, sino que aprehende la cosa real en su actualidad mundanal según un modo de realidad. Así, al aprehender un perro, diremos "esto - que es un perro- es un animal".

La determinación de lo que una cosa real es como momento mundanal lleva a Zubiri a preguntarse por los modos de realidad. Como ya es sabido, y en virtud de la función trascendental de la talidad, cada cosa es un modo y una forma de realidad. La razón, en su búsqueda, intenta aprehender toda estructura sustantiva en su actualidad mundanal como un determinado modo de realidad.

En definitiva, la determinación del fundamento de una cosa se moverá en el horizonte de la sustantividad, pues la cosa aprehendida campalmente es una sustantividad y también inteligida mundanalmente lo será como sustantividad.

En la noción de inteligencia sentiente van estructuralmente ligados el sentir y el inteligir a la hora de preguntarnos por la aprehensión de la realidad. Es por ello por lo que Zubiri se preocupa mucho no ya sólo de armonizar las nociones de inteligencia sentiente y sustantividad, sino de hablar de la realidad y su estructura sustantiva a partir de la inteligencia sentiente, y, por lo tanto, a partir de la conceptualización del "de suyo" y de la formalidad de realidad.

La índole misma de lo real, por lo tanto, obliga a entender la metafísica a partir de la inteligencia sentiente ${ }^{52}$ : la realidad es la formalidad de "de suyo", y no es otra cosa que dicha formalidad lo que constituye la realidad. Esta idea surge en el estudio zubiriano de la realidad a partir de la impresión de realidad, como presumimos que a estas alturas de la exposición todo lector recordará. El momento de la impresión de realidad que permite que esto suceda es el de trascendentalidad, esto es, el momento de apertura de la formalidad de realidad $^{53}$ : realidad es el "de suyo", que se encuentra abierto como "de suyo" a lo que la cosa es en su suidad y al resto de las cosas; esta apertura, recordemos una vez más, es física, nunca conceptiva, y por lo tanto es real: "La transcendentalidad es real: por ser real, la cosa es 'más' que lo que es por ser caliente o sonora. Pero a su vez ése 'más' es un 'más' de realidad; es algo que se inscribe 
en el 'de suyo' en cuanto tal; por tanto, es 'más' que la realidad de cada cosa. Se funda así en el 'de suyo' y es un momento del 'de suyo' mismo pero sin ser una adición extrínseca a él” (ibídem, p. 196).

Realidad es siempre formalidad abierta; es así como la realidad es constitutivamente respectiva. El momento de realidad, pues, cobra un carácter especial, que no es otro que el de "la fuerza de las cosas", "la fuerza de lo real", fundada siempre en el "de suyo" y explicitada como momento que expresa la trascendentalidad de las cosas, y no como momento añadido a la realidad: la realidad no es fuerza, sino que la fuerza es siempre un momento trascendental del "de suyo". 54

Esta fuerza de la realidad no es el único momento de la apertura trascendental: la formalidad de realidad consta también de un "poder", el "poder" de lo real. No es fuerza, sino tan sólo dominancia, la dominancia del momento de realidad sobre su contenido:

Lo real por ser real tiene un poder propio: el poder de lo real. Es la dominancia del momento de realidad sobre todo su contenido. Las cosas reales no consisten tan sólo en la fuerza con que este contenido se nos impone según su formalidad; consisten también en vehicular transcendentalmente el poder mismo de lo real, la dominancia de la formalidad sobre el contenido. Fuerza y poder son así dos dimensiones distintas de la impresión de realidad en su carácter de respectividad. (ibídem, p. 198)

Poder y fuerza de lo real se fundan, evidentemente, en el momento de "de suyo", de suerte que estos tres momentos - "de suyo", fuerza, poder-, competen a toda impresión de realidad.

Realidad es para Zubiri la formalidad del "de suyo" a diferencia de la formalidad de estimulidad. Formalidad de realidad y formalidad de estimulidad son dos cosas bien distintas, como de todo lector es ya bien sabido. Sólo la formalidad de realidad, propia de la inteligencia sentiente, permite la aprehensión de lo real. Como nos recuerda Zubiri "qué sea lo real es algo que sólo puede ser conceptuado desde la formalización, esto es, desde la inteligencia sentiente: es algo que ha de ser conceptuado como siendo 'de suyo' independiente y uno" (ibídem, p. 201).

Es precisamente al preguntarnos, dentro del marco de la inteligencia sentiente, por lo que es ese ser "de suyo" independiente y uno como podremos ${ }^{54}$ Cfr. íbidem, p. 197 
llegar estructuralmente a la idea de sustantividad: Aprehendemos una constelación de notas, que "de suyo" es independiente. Estas notas que se aprehenden son la constitución de lo real (constitución, recordemos, es el momento por el que las notas determinan la forma y el modo de lo real para cada realidad $^{55}$, lo que ya nos indica el primer carácter de lo real, que no es otro que ser constitucional. El contenido, así,

tiene capacidad para ser "de suyo". Y esta capacidad es, por tanto, capacidad de constitucionalidad. Esta capacidad es lo que llamo suficiencia en el orden a la independencia, al 'de suyo'; es suficiencia constitucional, suficiencia para ser "de suyo". (ibídem, p. 202)

Siempre desde la idea de la intelección sentiente, es muy coherente la explicitación de la sustantividad elemental, que es aquella que consta de suficiencia constitucional (aunque sea provisionalmente) en lo mínimamente aprehendido como real, esto es, en cada una de las notas de las cosas reales; así, por ejemplo, un color aprehendido independientemente es una sustantividad elemental, pues es verde real, rojo real, azul real, ...

La sustantividad elemental no es la más común, evidentemente, ya que por lo general nos encontramos con sustantividades sistemáticas, con constelaciones de notas que tienen la misma formalidad de realidad, una formalidad de realidad que "reifica" el conjunto de todas ellas, haciendo que éste, y sólo éste, sea lo que es "de suyo".

De forma coherente también cada una de las notas quedará caracterizada como "nota-de" todas las demás, en el estado constructo. Estado constructo es un momento estructural, no se trata -venimos repitiéndolo largo tiempo ya-de una relación de adhesión del contenido de unas notas de cada sustantividad en cuestión a las otras. No; toda nota es real en cuanto nota en la medida en que es unidad con todas las demás notas, esto es, en la medida en que forma parte de un sistema. ${ }^{56}$ Indicamos todo esto con cierta rapidez, pues es algo ya sabido por todos nosotros. Sin embargo, conviene que nos detengamos en lo que Zubiri añade, desde la perspectiva de la inteligencia sentiente:

La formalización de lo sentido en el sentir es el momento impresivo de la intelección sentiente; en este caso la formalización consiste en constelación. Ylo así impresivamente inteligido es sistema. Es decir, cuando tiene la formalidad del "de suyo",

${ }^{55}$ Cfr. íbidem.

${ }^{56}$ Cfr. ibídem, p. 203 
la formalización de las notas como constelación cobra el carácter del sistema sustantivo: es unidad de sistema. La unidad del sistema es unidad constructa. Sólo el sistema ahora tiene unidad constitucional. La formalización funda sentientemente esa aprehensión intelectiva de lo que llamamos cosas reales no como 'cosas' (...) sino como unidades de sustantividad sistemática. (Ibídem)

Toda sustantividad, tanto elemental como sistemática consta de "unidad numeral" de realidad, es decir, de unidad estructural, unidad en que la sustantividad queda mensurada en diversas dimensiones, de suerte que, desde una inteligencia sentiente, la sustantividad sólo puede entenderse como sustantividad dimensional. Como podemos leer en Inteligencia Sentiente, dichas dimensiones son: totalidad, coherencia y duratividad. ${ }^{57}$

En efecto, en la aprehensión de cualquier cosa real, esa cosa se aprehende en primer lugar como un todo, como un totum, aunque estemos aprehendiendo diversas notas (que, en efecto, no dejan de ser una constelación de notas), de suerte que la primera dimensión de la realidad es el todo actualizado en cada nota o en un grupo de notas. ${ }^{58}$ En segundo lugar, y en tanto que cada nota es "nota-de" todas las demás, hace falta una coherencia en el "de", con lo que nos encontramos con sistemas de notas coherentes, esto es, con que el sistema se actualiza - bien en cada nota, bien en un grupo de notas- como un todo coherente. ${ }^{59}$ Por último, ese todo coherente tiene cierta "dureza", es durable en el sentido de que "está siendo". Por lo tanto, todo lo real es "de suyo" total, coherente, durable: estas dimensiones son momentos reales de lo aprehendido mismo en su primordial aprehensión. ${ }^{60}$

Todo esto se dilucida, lo decimos una vez más, sólo si partimos de una inteligencia sentiente, y no de una inteligencia concipiente, como ha sido el punto de partida de toda la filosofía. Según esta inteligencia concipiente, lo inteligido no deja de ser jectum, ya sea entendido como sub-jectum o como ob-jectum, que es como se ha entendido en la filosofía clásica y en la moderna, respectivamente. Sin embargo, desde una inteligencia sentiente

la realidad no es jectum ( ni subjectum ni objectum), sino que lo real es lo que tiene la formalidad del "de suyo", sea una nota sea un sistema de notas sentidas en su realidad. Lo real no es 'cosa' sino algo 'en propio', sea o no cosa. a diferencia de

${ }^{57}$ Cfr. ibídem, p. 204-207

${ }^{58}$ Cfr. ibídem, p. 206

${ }^{59} \mathrm{Cfr}$. íbidem

${ }^{60}$ Cfr. ibídem 
lo que se pensó en inteligencia concipiente, a saber que lo real es sustancialidad y objetualidad, en inteligencia sentiente lo real es sustantividad. Por tanto, las notas no son accidentes "in-herentes" a un sujeto sustancial, ni son predicados de un objeto, sino que son momentos constitucionalmente 'co-herentes' en un sistema constructo sustantivo (ibídem).

Todo lo real está, al mismo tiempo, instaurado en la realidad, es mundanalmente real: cada cosa real es un momento de la realidad, y no sólo algo independiente por sus notas y el modo en que éstas son reales. ${ }^{61}$

La instauración de todo lo real en la realidad se le da radicalmente al hombre en la impresión de realidad, y por lo tanto no se trata de una elaboración conceptual, sino que se trata de una aprehensión física. Con esta afirmación no se niega que tengamos conceptos, sino que se apunta que los conceptos no son lo primario en orden a determinar nuestra conexión con la realidad: lo primario, lo más radical como momento de la realidad en cuanto realidad es el "de suyo", y este momento se aprehende en inteligencia sentiente, distanciándose de lo que ocurriría en una inteligencia concipiente: "Para una inteligencia concipiente, el que algo sea pura y simplemente real significa tan sólo que es un caso particular de realidad. Pero para una inteligencia sentiente ser pura y simplemente realidad significa 'estar instaurado' en la realidad" (ibídem, p. 214).

Como podemos comprobar, una y otra vez es la idea de inteligencia sentiente la que nos permite adentrarnos en la visión estructural de la realidad, la que permite conceptualizar adecuada y coherentemente, como su referente categorial último, la noción de "sustantividad". Esa es la llave de acceso a una nueva forma de entender la metafísica.

\section{Referencias}

Pintor, A. (1979), "Génesis y formación de la filosofía de Zubiri”, Lección inaugural del curso académico 1979-1980, Facultad de Filosofía de la Universidad Pontificia de Salamanca.

—_, 1993, Realidad y sentido. Desde una inspiración zubiriana, Publicaciones Universidad Pontificia de Salamanca, Salamanca.

Zubiri, X., 1996, Espacio. Tiempo. Materia, Alianza Editorial, Madrid.

—_, 1987, Naturaleza, Historia, Dios, Alianza Editorial, Madrid.

${ }^{61}$ Cfr. ibídem, p. 212 
_ 1986, Sobre el Hombre, Alianza Editorial, Madrid.

1984, El Hombre y Dios, Alianza Editorial, Madrid.

, 1983, Inteligencia y Razón, Alianza Editorial, Madrid.

, 1982, Inteligencia y Logos, Alianza Editorial, Madrid.

, 1980, Inteligencia sentiente, Alianza Editorial, Madrid.

, 1963, Cinco lecciones de filosofía, Sociedad de Estudios y Publicaciones, Madrid. 